\title{
Research on Strengthening the Construction of Tourism Management Information System
}

\author{
Ying PENG \\ Anshun University, China \\ pengyingpy163@163.com
}

\begin{abstract}
With the construction of information increasingly deepening, tourism management also needs to realize information urgently. The realization of the information of tourism management makes our country's tourism management enter into modernization and internationalization.
\end{abstract}

KEYWORD: Tourism Management; Information; Construction

\section{INTRODUCTION}

Nowadays, information technology has played a quite important role in every walk of life. As a rapiddeveloping industry in recent years, tourism greatly depends on the information technology. However, comparing with the developed countries, the level of our country's tourism management is slow. It is necessary for the government and relevant departments to pay more attention to the construction of tourism management information. In this paper, the author will introduce what is information and information. Then, we will discuss the current situation of our country's tourism management information and the necessity of strengthening the construction of information. At last, the author will put forward some practical suggestions to the construction of tourism management information.

\section{INFORMATION AND INFORMATION}

Information refers to news and messages. It is the object that communication system deals with. To speak it more generally, it refers to all the contents spread among human society. Information is not only closely related to people's life. It is also crucial to the management of an enterprise even an industry. The enterprise or the management department needs to depend on the information closely, and then make a scientific analysis and prediction about the future so as to guide decisions and ensure the establishment of the policies and regulations correctly. To make a scientific decision, the decision maker must get the correct and credible information quickly.

Information refers to that in the economic and social activities, we build advanced information infrastructure through applying information technology and electronic information equipment to develop and utilize the information resources more efficiently. Then, the information products and services will play a leading role in the social economy. As a result, these are bound to speed up the economic development and social progress. Information is the general trend for the development of the world economy and society development. It is also the load we must take to realize information and internationalization of management.

\section{THE CURRENT SITUATION OF TOURISM MANAGEMENT INFORMATION IN OUR COUNTRY}

According to the volatility of the tourism, it is of great importance to know and grasp the information in time. The relevance of the tourism makes it necessary to apply the information technology in tourism. As we know, various information technologies have been applied in the tourism, such as the Computerized Reservation System (CRS), video conferences, digital electronic network and so on. Among those, the Computerized Reservation System is most broadly applied in tourism operation, while rarely in tourism management. The tourism management information obviously lags behinds the development of tourist industry. Our national tourism administration has stressed the development of the tourism management information since 1990. 
Since then, we started to build the information center to provide relevant management and services for the tourism. From the Fig.1, we can see that every provide has stressed the development of the tourism information.

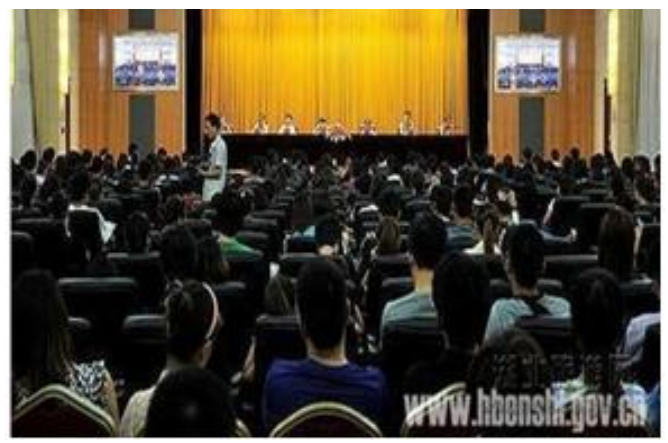

Fig.1 The issue on Enxi city

\section{THE NECESSITY OF STRENGTHENING THE CONSTRUCTION OF TOURISM MANAGEMENT INFORMATION}

\subsection{It is the objective requirement of the tourism management information.}

The operation of tourism is based on the mobility and wide-area connection. It specially stresses the resource sharing and all parts working together. The improvement of the tourism management efficiency and interests cannot live without cooperation of all parts. From these, we can see that tourism involves many areas and each part links closely. Therefore, the internal elements must coordinate as well as the tourism and other industries. If we cannot manage the tourism information appropriately, we cannot adapt to the complicated tourism operation and the high-intensitive management mode. In recent years, many problems have emerged up. Most of them are for the lack of effective information communication between the customers and tourist industry. Besides, the tourism department can know about the tourist market condition in time through the tourism management system then seize the supply and demand of the tourism market. So we can lay down relevant scientific policies to adjust the tourism market.

Especially in the trend of economic globalization, the internationalization of tourism is outstanding. The tourist global market and national market tend to integrate. The tourism all around the world more and more closely depends on each other. The important status of information outstands day by day. The information technology has permeated into the modern tourist industry.

\subsection{It is the inner demand of the tourism management information.}

First of all, the characteristics of tourism are intangible, immobile and cannot be saved. In fact, producing and consuming happen simultaneously. Under the guidance of the modern marketing concept, the tourism manager designs the tourism products according to the market demand. Besides, the tourism managers connect with each other through rapid, convenient information exchange. However, information technology plays a crucial role in it. Second, tourism is fragile. It is easily influenced by the natural factors, political factors and economic factors. So it is particularly important to get information efficiently so as to make scientific decisions. Third, the application of e-commerce makes the tourism resources shared more broadly. Thanks to the rapid development of e-commerce, developing tourism e-commerce can reduce the cost of information getting and exchanging. It also can improve the competitive power of the tourism products. The information technology plays an important role in it.

\section{THE SUGGESTIONS TO STRENGTHENING THE CONSTRUCTION OF TOURISM MANAGEMENT INFORMATION}

\subsection{The government should give full play to support and guidance.}

The government plays a critically important role in the development of our tourism management information. First of all, the government should stress the development of our national tourism management information and play well the leading function. The government must positively support the tourism management information revolution in our country. Starting with the tourism management department, she must encourage each tourist industry and tourist company to attempt the tourism management information. Besides, she appeals the tourism industries to work and communicate online. The tourist department at different levels should shoulder their responsibility and speed up the process of the tourism management information. In addition, the government should increase the capital input to the tourism management information. The realization of tourism information can bring more convenience to the consumers. In contrast, it cannot bring practical economic interests to the tourism industry in a short time. So, many industries don't want to invest much capital and energy to strengthen the tourism management information. At this time the government should provide economic support to 
the industries, especially the middle and small-sized enterprises.

\subsection{The tourist industries should stress the construction of geographic information system and database.}

The geographic information system is a comprehensive computer system that synthesizes graph, attribute and other kinds of information. By the analysis of the geographic information, we can not only provide much tourist information for the customers, but also help the customers make decisions. The crux of the tourism management information is to build a database with rich contents, which updates timely. The tourism management information generally includes geographic database and graphic-text database. The geographic database is used to create topic map through analyzing and synthesizing the geographic information of each tourist attraction. The graphic-text database refers to the various data and pictures used to advertise the tourist attractions. By combining the geographic database and graphic-text database together, we can make the graphic digitalized. Besides, we can store the tourist information in the computer which makes it easier for us to search in the future.

\subsection{We should enhance the management of the tourist information.}

The tourism management information is effective for a given period of time and it changes fast. So it is necessary for the national or local tourism management departments to collect information regularly and exchange in time. In addition, they should update the tourist information through network timely. It is also important to control the quality of information. The department should examine whether the tourist information is accurate provided by the industries. It is also needed to establish relevant policies and regulations to ensure the information is correct and normative.

\section{CONCLUSION}

In a word, the network technology has been widely applied in every industry. Updating the way of social management is imperative. The tourism industry must pay efforts to realize the information.

\section{REFERENCES}

[1] S.P. Deng. Information and soft environment. In: Electronic Outlook and Decision-making, 1996, 43-57.

[2] L. Dong. Brief talk about tourism management information. In: Technical Education Forum, 2007, 22-40.

[3] M. Y. Gan and J. Zhang. Tourism under the context of globalization. In: Asia-pacific Economic Review, 2000, 1023.

[4] P. Huang. The important power of the tourism development. In: Tourism Research, 1998, 105-122.

[5] Z. Y. Qian. Analysis of tourism management information. In: Group Economy, 2005, 61-73.

[6] Y. T. Li. Analysis of the tourism information management mode. In: Journal of Business Condition, 2010, 10-32. 